\title{
Experimental Research on the Core Ploughshare Furrow Opener Based on the Discrete Element Method
}

\author{
Shi-Qiang PAN ${ }^{1,2, a}$, Zi-Fu CAO ${ }^{2, b}$, Shan-Shan JIANG ${ }^{3, c}$, Jian-Qun YU ${ }^{1, d, *}$ \\ ${ }^{1}$ College of Biological and Agricultural Engineering, Jilin University, Changchun 130025 \\ ${ }^{2}$ College of Engineering and Technology, Jilin Agricultural University, Changchun 130118 \\ ${ }^{3}$ Changchun University of Science and Technology, Changchun 130600 \\ ashiqiangpan@163.com, b769801319@qq.com, '907485727@qq.com, dyujianqun@jlu.edu.cn \\ ${ }^{*}$ Corresponding author
}

Keywords: Core Ploughshare, Furrow Opener, DEM, Soil Particles.

\begin{abstract}
The working process of the furrow opener is the state of movement between the working parts and the soil particles. The discrete element method (DEM) could not only truly express the geometrical characteristics of the soil particles but also be suitable for the experimental study on the furrow opener. In this paper, the physical and mechanical properties parameters of the surface soil particles were measured by the equipments, such as the soil triaxial apparatus, the direct shear apparatus, and so on. We established the discrete element 3-D model of the surface soil particles. The core ploughshare furrow opener was simulated by the discrete element software. We also revised the discrete element simulation model using the glass soil bin and the high-speed camera technology. The results of tests compared with discrete element simulation showed that both had the good correlation and the same laws. At the same time, we verified the validity of the simulation model parameter selection. We provided the effective method for the study and optimization design of the furrow opener.
\end{abstract}

\section{Introduction}

In recent years, a large number of discrete element methods are applied to agricultural production, and from simulation of working parts of furrow opener, subsoiler, covering device and dozer and other working parts touching the soil, the experimental data and simulation results obtained match highly [1-3]. In this paper, discrete element particle dynamics method - the discrete element method is used to simulate the moving behavior between granular materials. The method is suitable to simulate the interaction between a rigid or flexible bodies soil, can accurately describe the soil tillage process and optimize the design of the shape, control of soil rupture, mixing and flow reasonably based on the contact model between the soil and the opener, simulating soil tillage process $[4,5]$.

Due to the variability of soil medium spatial displacement, nonlinear characteristics of soil material, touch of soil particles and tillage parts and its mobility, the parameters are difficult to be determined [6]. Therefore, the establishment of soil tillage model and contact model between soil and tillage parts is a very complex process. This thesis through soil tri-axial, direct shear apparatus, soil sieve, oven, electronic scales, soil hardness tester and other equipment, test the physical and mechanical parameters properties of topsoil particles, establish a three-dimensional discrete element model of topsoil particles, and simulate the core ploughshare type furrow opener in discrete element method. And with the help of the glass soil bin and high-speed camera technology, it verified and corrected the discrete element simulation model.

\section{Discrete element model and its parameters confirmation}

\section{The soil discrete element model establishment and its parameters confirmation}

Since the soil property is extremely complex, this paper conducted a grading of topsoil, and each grade of soil particles were tested in shape. Due to the particle shape is irregular, in order to simplify the calculation, the paper applied 4 kinds of soil particles mainly in single and dual spherical ball shape, as shown in figure 1. 


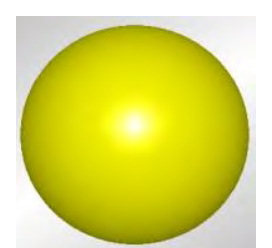

a)single ball

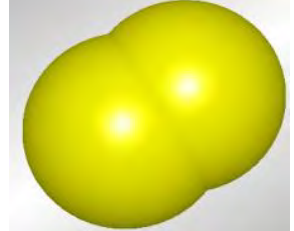

b)dual ball

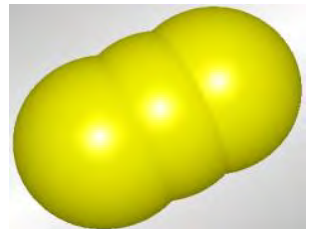

c)level triple ball

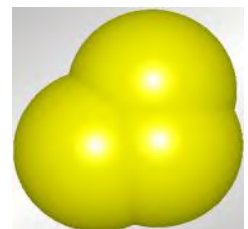

d)triangle triple ball

Fig. 1 Soil Particles Model

Since the soil is a complex matter composed of gas, liquid and solid components, and with chemical bond and capillary water, which makes the existence of certain cohesion between the soils [7]. Thus, when establishing the soil particles model, this paper choose Hertz-Mindlin adhesive contact model which bonds two particles through a certain sized "bond key", this bond can afford a certain normal stress and tangential stress, when and only when it reaches the maximum normal stress and tangential stress, the bonds between particles will break. Since then, the particles can be regarded as a rigid sphere solved by contact.s

In the discrete element simulation process, you also need to set a number of parameters, such as material properties of geometry and particles, the geometry of motion, particle factory settings. For the soil, some parameters can be obtained by laboratory equipment, such as density, Poisson's ratio, elastic modulus, friction coefficient [8-9]. In this paper, the central region black loam of Jilin province is selected as the research object which the above parameters were measured. There are some microscopic parameters cannot be obtained by test, such as the recovery coefficient, stiffness coefficient, the critical stress, etc., the setting of these parameters mostly rely on empirical formulas and repeated trial, comparing the actual test data to determine a reasonable range, the simulation parameters such as Table 1.

Tab. 1 The Value of Simulation Parameters

\begin{tabular}{|c|c|c|c|}
\hline parameter & & value & \\
\hline Soil moisture content $(\%)$ & $10 \pm 1$ & $15 \pm 1$ & $20 \pm 1$ \\
\hline Soil density $\left(\mathrm{kg} / \mathrm{m}^{3}\right)$ & 1263 & 1235 & 1199 \\
\hline Soil particle diameter $(\mathrm{mm})$ & $2.25 \sim 3.75$ & $2.25 \sim 3.75$ & $2.25 \sim 3.75$ \\
\hline no.of soil particle( 10 thousand) & $12 \sim 26.7$ & $12 \sim 26.7$ & $12 \sim 26.7$ \\
\hline Poisson's ratio of soil & 0.38 & 0.36 & 0.34 \\
\hline Soil shear modulus(Mpa) & 0.9 & 0.86 & 0.81 \\
\hline recovery coefficient of soil particles & 0.15 & 0.13 & 0.1 \\
\hline recovery coefficient of soil and opener & 0.18 & 0.15 & 0.12 \\
\hline static friction coefficient between soil particles & 0.532 & 0.364 & 0.268 \\
\hline dynamic friction coefficient between soil particles & 0.25 & 0.22 & 0.2 \\
\hline static friction coefficient between soil and opener & 0.5 & 0.5 & 0.5 \\
\hline dynamic friction coefficient between soil and opener & 0.32 & 0.32 & 0.32 \\
\hline The normal stiffness coefficient between soil particles $(\mathrm{N} / \mathrm{m})$ & 13000 & 19000 & 25000 \\
\hline The tangential stiffness coefficient between soil particles $(\mathrm{N} / \mathrm{m})$ & 9000 & 14000 & 19000 \\
\hline critical normal stress between soil particles(pa) & 50000 & 55000 & 62000 \\
\hline critical tangential stress between soil particles(pa) & 25000 & 29000 & 35000 \\
\hline acceleration of gravity $\left(\mathrm{m} / \mathrm{s}^{2}\right)$ & 9.8 & 9.8 & 9.8 \\
\hline Time step & $5 e^{-5}$ & $5 e^{-5}$ & $5 e^{-5}$ \\
\hline
\end{tabular}

Soil particles production relies on FactoryTM technology provided by applying simulation software, setting generating various forms of particle collection in accordance with the soil layering. Topsoil in different soil layering is of different size and shape, the bottom layer has larger diameter particles, which 
soil particles suffer small perturbations, increasing the particle diameter, can reduce the number of particles, and improve computing speed. Upper layers soil particles use particles with a variety of shapes and small diameter, try to describe the true state of the soil [10]. This article will divide the soil in accordance with the depth of the soil of the $30 \mathrm{~mm}, 60 \mathrm{~mm}, 90 \mathrm{~mm}$ deep, shown in figure 2.

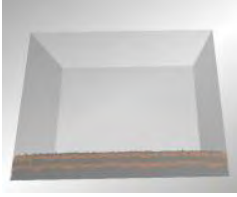

a) $30 \mathrm{~mm}$

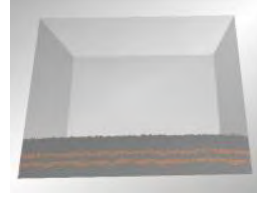

b) $60 \mathrm{~mm}$

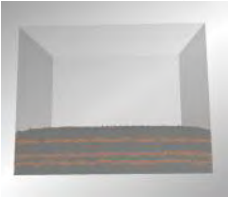

c) $90 \mathrm{~mm}$

Fig. 2 The Model of the Soil Particles for the Different Depth

\section{Establishment of furrow opener simulation model}

According to the actual core ploughshare type furrow opener's shapes and sizes, installed two opener. One is complete opener for measuring force; another is half opener using to contact soil bin test bench side glass. Build three-dimensional models of furrow opener by Solidworks software, and import simulation software, see figure 3.

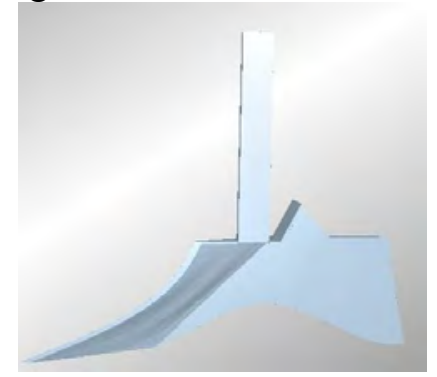

a)complete core ploughshare type furrow opener

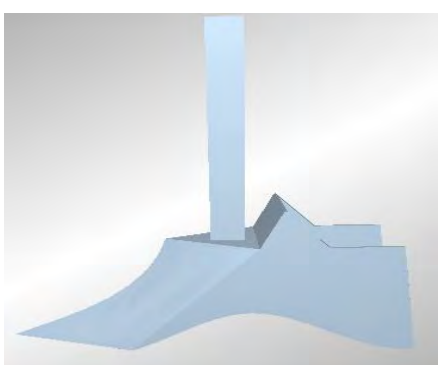

b)half core ploughshare type furrow opener

Fig. 3 the Model Diagram of the Furrow Openers

\section{Furrow Opener Soil Bin Test Equipment and Test Program}

\section{Test Equipment}

In this paper, using self-built glass bin to test the soil, in order to ensure the consistency of the experimental data, the experimental use two-dimensional force sensors and dynamic strain gauge to measure c horizontal and vertical resistance of complete opener in the work process, and through high-speed cameras record the movement of half opener to soil particles mean driving force to soil Test bench shown in Figure 4.

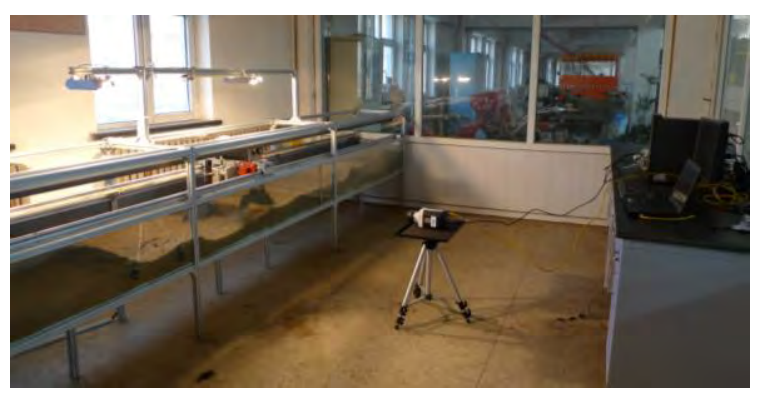

Fig. 4 The Test Bench of the Glass Soil Bin

\section{Test Program}

The main parameters affecting openers are soil moisture content, trenching depth and openers operating speed, the paper selected three levels of each factor. According to sowing time of the central region of Jilin province, the actual state of the soil and agronomic requirements of the opener to determine the moisture content and ditching depth range. Due to the restrictions glass soil bin, openers operating speed is smaller than actual speed. The selected factors levels as shown in Table 2. 
Tab. 2 The Table of Factor Levels

\begin{tabular}{cccc}
\hline & Moisture content & Trenching depth(mm) & Opener operating speed(m/s) \\
\hline 1 & $10 \% \pm 1 \%$ & 30 & 0.2 \\
2 & $15 \% \pm 1 \%$ & 60 & 0.5 \\
3 & $20 \% \pm 1 \%$ & 90 & 0.8 \\
\hline
\end{tabular}

\section{Test Results}

\section{Measurement of Opener Working Resistance}

This chapter carries out above test program to measure the horizontal working resistance and vertical resistance of opener, under different condition, we get different Opener force curve (figure 5).
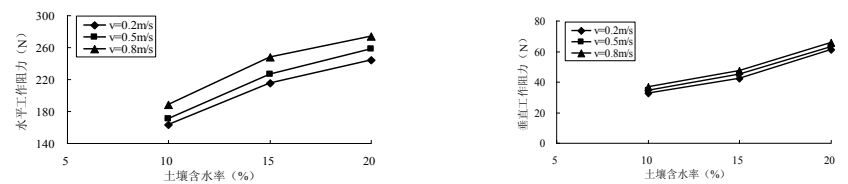

a)influence curves of moisture content on resistance work for opener
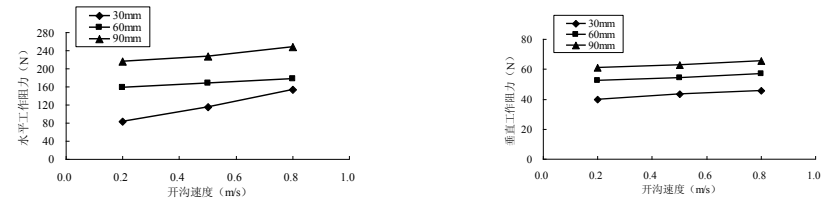

b)influence curves of operating speed on resistance work for opener
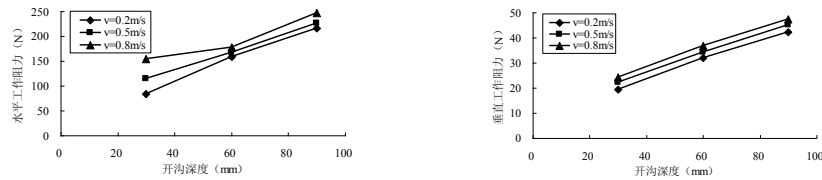

c)influence curves of trenching speed on resistance work for opener

Fig. 5 The Influence Curve of the Working Resistance for the Furrow Openers

\section{The Movement of Soil Particles}

Using of fertilizers on soil to layer it which help to understand the movement of soil particles in different soil layer. Using high-speed cameras capture the movement under different trenching depth, different opener operating speeds and different soil moisture content (Figure 6).
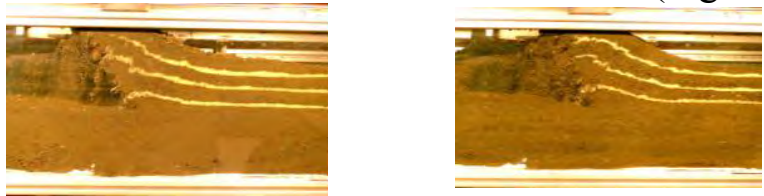

a)soil particles movement in different soil moisture
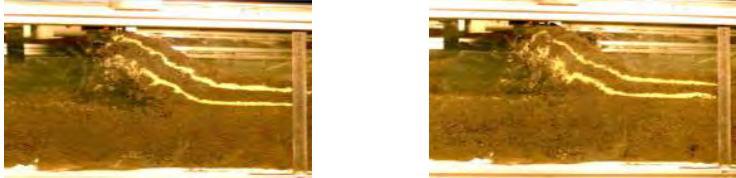

b)soil particles movement in different trenching depth
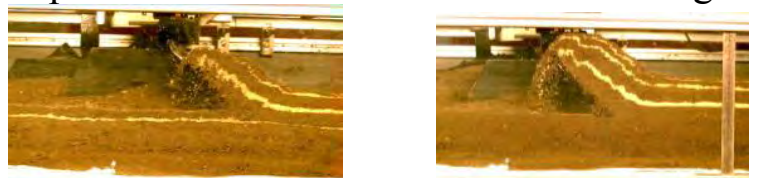

c)soil particles movement in different operating speed

Fig. 6 The Motion between the Furrow Openers and the Soils under the Different Working Conditions 


\section{Analysis of Experimental Results and Simulated Results}

This article selects discrete element contact model of soil particles as Hertz-Mindlin bond contact model. In the simulation experiment, some parameters is difficult to accurately determine, for example, the normal/tangential stiffness between soil particles, the critical normal/tangential stress, etc., they are determined after repeated trial and optimization comparing with the test results. Therefore, this paper conducted a number of computer simulation and analyze the experimental results comparing with the simulation results.

\section{Comparison of Opener Force}

The opener soil bin test bench results were compared with the simulation results under the same conditions, as shown in Figure 7.
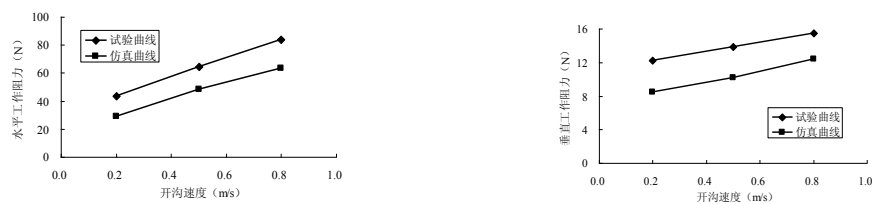

a)different operating speed
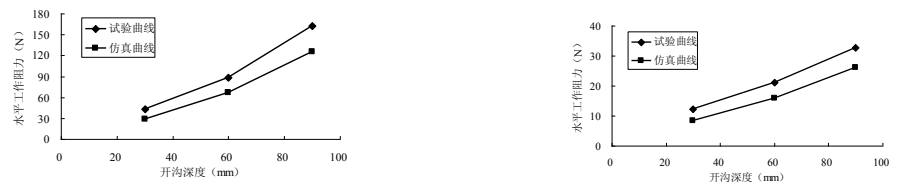

b)different trenching depth
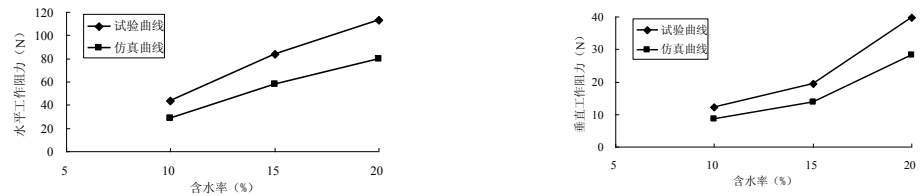

c)different moisture content

Fig. 7 The Contrast Charts of the Force for the Furrow Opener

Comparative results indicate that the experiment and simulation has good correlation, and consistent rule. Deviation is mainly produced because of the soil particles complexity and the simplification and amplification of particles during simulation.

\section{Comparison of Soil Particle Movement}

The same as soil bin test, the test set up the simulation model of soil particles, with different colors to distinguish the soil. Under different tillage depth, using high-speed cameras captured images compared with the simulation results, shown in Figure 8.
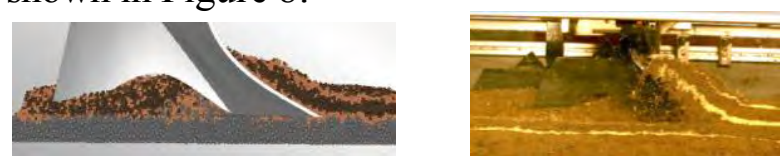

a)tillage depth is $30 \mathrm{~mm}$
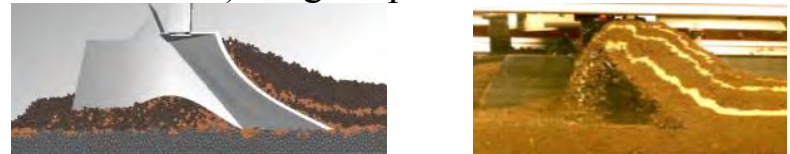

b)tillage depth is $60 \mathrm{~mm}$

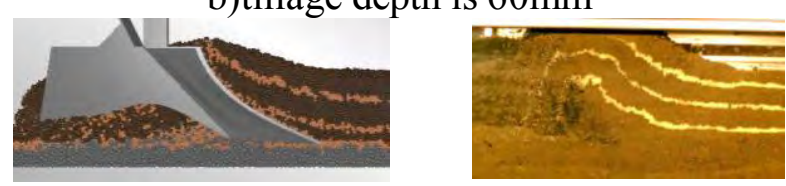

c)tillage depth is $90 \mathrm{~mm}$

Fig. 8 The Contrast Charts of the Motion Condition for the Soil Particles 
Comparative results showed that soil particles' actual trajectory is identical with the simulation results which verify the correctness of the chosen test soil particles discrete element contact model and its parameters.

\section{Conclusion}

(1)Established discrete element simulation models for the central region of Jilin province black loam, and gives the appropriate discrete element simulation parameter values.

(2)With glass soil bin and high-speed camera technology, we carried out experimental study of opener working process providing the effective testing methods for the study of opener and soil movement.

(3)Using the discrete element method in the study of work process of core ploughshare type furrow opener ,the simulation results are compared with the test results and it showed that a good correlation between the two, and consistent rules, which provides an effective testing methods for the study of opener and its optimization design.

\section{Acknowledgement}

This research was supported by the National high-tech research and development program of 863 projects (2006AA04Z125) and the international natural science fund project (11172112 and 51175219).

\section{References}

[1]Tanaka, H., Momozo, M., Oida, A., Yamazaki, M., 2000a. Simulation of soil deformation and resistance at bar penetration by distinct element method [ J] Terramech.37,41-56.

[2]B.A.Collins,D.B.Fowler.Effect of soil characteristics, seeding depth, operating speed, and opener design on draft force during direct seeding [J]. Soil \& Tillage Research, 1996, 39:199-211.

[3]Damora D,Pandey K P. Evaluation of performance of furrow openers of combined seed and fertilizer drills[J].Soil and Tillage Research, 1995, 34(1):127-139.

[4]Asaf, Z., Rubinstein, D., Shmulevich, I., 2006. Evaluation of link-track performances using DEM[J]. Terramech. 43, 141-161.

[5]Shmulevitch, I., Asaf, Z., Rubinstein, D., 2007. Interaction between soil and a wide cutting blade using discrete element method[J].soil tillage res.97, 37-50.

[6]I. Shmulevich 2010. State of the art modeling of soil-tillage interaction using discrete element method [ J]Soil \& Tillage Research 111 (2010) 41-53

[7]Zhang Rui,The Research of Soil Dynamic Behavior based on the Discrete element analysis [D] Changchun: Jilin University, 2005.

[8]Zhang Rui,Li Jianqiao,Zhou Cahngqiao,etc.Discrete Element Simulation of Impact on Soil Dynamic Behavior by bulldozing plate surface morphology [J]. Agricultural Engineering,2007,23(9):13-19.

[9]Qian Liji,The Research of Opener Digital Design Methods based on Discrete element Method [D].Changchun:Jilin University,2008.

[10]Asaf, Z., Rubinstein, D., Shmulevich, I., 2007. Determination of discrete element model parameters required for soil tillage[ J] Soil Tillage Res. 92, 227-242. 